Session 3147

\title{
Professional Development Collaborative Focuses on High School/College Faculty Partnerships
}

\author{
Donald Martel, Marty Waffle, Peggie Weeks \\ Northville Central School/Fulton-Montgomery Community College/Hofstra University
}

\begin{abstract}
Five colleges - Alfred State College, Dutchess Community College, Fulton-Montgomery Community College, Mohawk Valley Community College, and Suffolk County Community College - in partnership with Hofstra University and the New York State Technology Education Association, are establishing the New York State Professional Development Collaborative (NYSPDC) with support from the National Science Foundation's Advanced Technological Education Program. The project is initially providing workshops in the areas of materials/manufacturing and information technologies to high school technology teachers through a program that brings together community college technical experts, professional association teacher/leaders, and university pedagogical experts. The overarching goals are to provide contemporary professional development to technology educators using standards-based exemplary materials, to forge effective alliances between community/technical colleges and the technology education community, and to create a professional development model that the leadership of New York's technology education community will sustain.
\end{abstract}

\section{Introduction}

What is technology? What does it mean to be technologically literate? It is widely agreed that many of the children in the United States know a great deal about operating computers and navigating the World Wide Web. In fact, adults will admit that children are pretty savvy when it comes to operating and troubleshooting their computers.

It is easy to misinterpret this ease of working with computers as the sole mark of technological literacy. The technical community continues to be frustrated by the lack of understanding by the general public about what constitutes "technological literacy." A Gallup Poll conducted recently on technological literacy revealed that most Americans have a very limited view of technology. ${ }^{1}$ An overwhelming 68 percent of those polled answered "computers" in response to being asked to name the first thing that occurred to them when they thought of technology.

It is important that the engineering education community continue to dispel the myth that technological literacy is equivalent to knowing how to operate a computer. Understanding the technological world around us is important for all Americans. In its landmark study which produced the publication Technically Speaking, the National Academy of Engineering cited a number of benefits of enhanced technological literacy of society: improved decision making; increased citizen participation in the political process; support of a modern workforce, a narrowed digital divide; and enhancement of social well-being. ${ }^{2}$ 
Since 1993, the National Science Foundation has funded the Advanced Technological Education (ATE) Program, which focuses on technician education and technological literacy for our nation's high school and college students. The ATE Program insists on partnerships among various stakeholders in order to optimize the impact of the projects on the intended audiences. Of particular importance is the collaboration among high school teachers and 2- and 4-year college faculty. There is little argument that if the post-secondary education community collaborated with the secondary education community, our educational system would function in a more efficient and effective way.

In response to increasing the technological awareness and literacy of students, particularly at the secondary level, the New York State Professional Development Collaborative was formed. This National Science Foundation funded effort is working to improve collaborations among technology educators at the secondary and post-secondary levels; and to provide contemporary, pedagogically sound curricular workshops for teachers that will ultimately impact student learning of technology in New York's high schools. The initial focus has been on collaborations between high school technology teachers and community/technical college faculty. The NYSPDC project's ultimate goal is to develop sustainable professional development centers at the community and technical colleges around the state - centers that teachers can benefit from.

\section{The Partnerships \& Rationale for NYSPDC}

New York State's technical and community colleges have a long-standing reputation of excellent engineering technology programs, and faculty who are well trained in the latest and most relevant technologies. The state also boasts a strong community of high school technology educators through its New York State Technology Education Association (NYSTEA). While these two groups are well established, a solid link between them has been missing. With stronger links, the transition for students from high school into technical education programs in two-year and four-year colleges can be facilitated. Such collaboration is enabling technology educators to better prepare their students for technical programs at the community college, and community college faculty to make well-informed connections to what incoming students have learned. While collaboration exists in a few areas of the state, largely as a result of Tech Prep initiatives, it is not pervasive.

Also missing has been a well-developed statewide professional development strategy for high school technology teachers. The State of New York requires 175 hours of professional development for teachers, hours that can be accumulated in many ways. NYSTEA has recognized the need for quality professional development and is committed to formalizing a mechanism to provide high-quality in-service programs for its membership. Furthermore, the technological literacy standards require new skills and professional development to implement standards-based programs in the high schools. Ultimately, a sustainable professional development model that includes both high school and college technology educators will better prepare New York's future technical workforce.

In addition, new regulations passed by the New York State Board of Regents require all high school students to meet the technology standards prior to graduation, and allow them to substitute technology education courses with defined mathematics and/or science content for the 
third required unit of mathematics and science. ${ }^{3}$ Technology education is emerging as a discipline that can contribute to mathematics, science, and technology literacy. NSF has identified it as an "area of special interest," defining its focus as "the human-built environment that provides contexts for problem-solving and for understanding MST concepts." In New York State, there are over 3,000 certified technology teachers at the secondary level. ${ }^{5}$ Over the past two decades, the profession has moved from its crafts roots toward engineering. In technology education classes, relevant mathematics is being embedded in engaging design-and-construct activities.

Five colleges-Alfred State College, Dutchess Community College, Fulton-Montgomery Community College, Mohawk Valley Community College, and Suffolk County Community College - are the key partners in the New York State Professional Development Collaborative. The schools are geographically dispersed throughout the state. One or two engineering technology faculty members from each school comprise the college's leadership. To round out the college leadership teams, high school technology teachers were selected to work with the college faculty and be an integral part of the leadership. A total of 19 faculty and teachers have been working together since the summer of 2003 to develop quality professional development workshops for the secondary school technology education community throughout the state of New York.

Another key partner is Hofstra University. The leadership team at Hofstra brings a wealth of pedagogical expertise to the project, as well as overall project oversight. Hofstra's Center for Technological Literacy was created in 1989 with the goal of improving technological literacy of students in grades K-16.

The New York State Technology Education Association (NYSTEA) is another important project partner. Through its extensive network across the state, it has helped to recruit the secondary educator project leaders as well as workshop participants. Project dissemination has largely been the responsibility of NYSTEA.

\section{Goals, The Professional Development Model, \& Informed Design}

The overarching vision of NYSPDC is the creation of a statewide professional development collaborative that is responsive to the needs of the technology education community and that is sustained by a dynamic and cohesive partnership among technical/ community colleges and high school technology educators.

The project's primary goals are to: (1) produce a cadre of expert technology leaders from high schools and colleges; (2) link high school and college technology educators in a meaningful and sustainable collaboration; (3) provide professional development workshops for high school technology teachers in materials/manufacturing and information technologies; (4) encourage statewide dissemination and implementation of exemplary technology education instructional practices; and (5) create a transportable and sustainable model of professional development.

In the spring of 2003, a planning group comprising the project management team and the Professional Development Collaborative (PDC) leadership teams (secondary school 
teacher/leaders and college experts from each of the five regions) participated in a two-day planning meeting. The secondary school teachers are NYSTEA association leaders, and the college faculty have content expertise in the areas of materials/manufacturing and information technologies. In the summer of 2003, the project management team and additional consultants conducted an intensive, seven-day workshop at Fulton-Montgomery Community College for the PDC leadership teams. NSF-developed instructional materials were used to ensure that exemplary, pedagogically sound curriculum is at the core of instruction. Classroom-tested materials in materials/manufacturing and information technologies, developed as part of a previously funded NSF project, New York State Curriculum for Advanced Technological Education (NYSCATE), were used. Standards for Technological Literacy identifies broad areas for study that include a focus on manufacturing and materials technologies and information and communication technologies. In NYS, high school courses emphasize these same technological areas. $^{6}$

The professional development model for the leadership workshop and subsequent technology educator workshops was based on the use of informed design as the predominant instructional strategy; the use of technological areas (materials/manufacturing and information technologies) as contexts for learning; the integration of mathematics, science, technology, and language skills within instruction; and the use of constructivist learning theory as the pedagogical underpinning. The informed design model, developed and refined in the NSF-funded NYSCATE project, emphasizes science inquiry and mathematical analysis in the context of design and is aligned with national standards. The NYSCATE modules incorporate the informed design cycle, which is similar in approach to the iterative engineering design process. Students work in teams on design challenges that emphasize the application of science and mathematics principles, as opposed to a trial-and-error approach, to the design solution. The following extract from one of the modules is representative of the workshop materials:

\section{Design Challenge Module: Using Liquid Crystals to Create a Practical Device}

ABSTRACT: As we examine the world around us, many common devices we use each day are being replaced by more advanced items that draw from our ever expanding knowledge of science and technology. This module integrates mathematics, science, and technology (MST) through the design and development of a liquid crystal device. Students will be challenged to develop knowledge and skills necessary to design, construct, and test an object that demonstrates an effective use for a liquid crystal device in the form of a thermotropic display. Students, working in design teams, will be expected to make their design decisions based upon mathematical and scientific principles in an informed design process rather than proceed through trial and error. Mathematical, scientific, and technological Knowledge and Skill Builder (KSB) activities are completed by the groups to provide the needed information to guide them as they design, construct, and test the device. Topics in the KSBs include: the informed design cycle; electrical circuits; voltage, current, resistance, and power; series and parallel circuits; voltage divider circuits; liquid crystal properties; thermotropic concepts; use and combination of chemicals; and factor studies that relate temperature and color changes of thermotropic displays. DESIGN CHALLENGE OVERVIEW: Those who invent a device by taking a basic technology and putting it to use in a new way often improve our lives. The ability to design a new device by applying an existing technology is an important, creative engineering skill. Think of basic technological inventions such as Velcro, lasers, LEDs, CRTs--each has been put to so many uses. Can you name some of these uses? In this module, you will be challenged to take a basic technology, liquid crystal, and use it to design a new device.

Each day, we come into contact with many things for which temperature is important. 
- Some things, such as a cup of coffee, should be a certain temperature. Can you think of others?

- Some things, such as a person's forehead, indicate a problem when they are too hot or cold. Can you think of others?

- Measuring the temperature of something can indirectly measure something that may be difficult to measure directly. Measuring the temperature of a wire can indicate the amount of current flowing through it. Can you think of other examples?

A device providing a quick and inexpensive means of monitoring temperature visually could be used in many ways in today's world. This module challenges you to create such a device.

DESIGN CHALLENGE: As part of a team, you are to design, construct, and test a device that will demonstrate a practical use for liquid crystals in the form of a thermotropic display.

SPECIFICATIONS: The device constructed must incorporate the ability to detect heat and to visually display temperature (or a temperature range, or changes in temperature).

CONSTRAINTS: Each team must use only approved materials. The display created should be no larger than 1 inch by 2 inches.

The modules being used as part of NYSPDC can be viewed and downloaded in their entirety from www.hofstra.edu/nyspdc

The five PDC leadership teams met in their communities during the fall semester of 2003 to share experiences and refine plans for forthcoming workshops. The secondary school teacher/leaders tested curricular materials in their classrooms during the 2003-2004 academic school year. Each four-person regional leadership team then convened workshops for secondary school teachers within its region during the summer of 2004. The workshops were held at the partnering colleges in each of the regions. Participants were asked to commit to using the ATE materials in their own high school classes and to conducting classroom action research during the school year to assess student learning. In addition, the teams of workshop leaders and participants in each district communicated regularly during the 2004-2005 academic school year to share what they were learning from their classroom implementation activities, and to give all a chance to network more extensively. The project leadership team sent letters of recognition to participants' principals and superintendents.

\section{Successes \& Challenges}

The professional development workshops have been well received by the technology education community. Preliminary evaluation demonstrates that the teachers are returning to their classrooms and using the NYSCATE modules in their technology courses. The teachers are providing constructive feedback about the modules, and a few have made presentations at technology education conferences about their experiences. Virtually all teachers have embraced the model of informed design.

Probably the greatest success to date of NYSPDC has been the rich and lasting partnerships that have developed over the past two years between college faculty and high school teachers. One of the teacher/leaders made the following comment on his evaluation following the 2003 Leadership Workshop: “Group has 'jelled' - there's countless levels of interaction and networking (people networking) that's been just wonderful." Other members of the leadership teams, from both high school and college team members, echoed this sentiment. 
Still, there are challenges. The two most pressing are: (1) recruitment; and (2) gathering meaningful classroom assessment data, particularly with respect to impact on student learning. Our goal for the 2004 workshops was to have 20 teachers at each of the five workshops, for a total of 100 participants. Despite valiant recruitment efforts by NYSTEA and by the individual professional development teams, only 52 teachers participated in the workshops. At a recent statewide technology conference, we polled attendees to determine the barriers to their participation in NYSPDC workshops. Out of 59 surveyed teachers, only 14 teachers (23\%) reported that they had heard about the NYSPDC workshop. Results show that teachers who knew about the workshop, but decided not to participate, did not because they either attended another workshop, they found the scheduling inconvenient, or they had a summer job. To explore what can be done to improve recruitment, survey respondents were asked to identify factors that may affect their participation in future workshops. "Scheduling the workshop in a location and time more convenient to the teachers," and "offering materials that are more aligned with their school curriculum and teaching" were cited as being the most attractive features for participation in future workshops.

Teachers have the best of intentions when they return to their classrooms following a professional development experience. It is difficult, though, to convince them of the importance of doing extensive classroom assessment to ascertain the impact of the curricular changes on student learning. We have tried to simplify the process by providing surveys and other assessment documents, and we are optimistic that these tools will help them with their classroom research. We will augment these documents with frequent communication, and we will make certain that the importance of collecting classroom data is underscored.

\section{Future Activities}

As the NYSPDC project enters its third year, we continue to find ways to reach out to the education community and to provide exemplary professional development activities that will ultimately benefit students across the state. The PDC leadership teams have pledged to work more closely with their regional school districts to ensure effective design of in-service teacher education programs. Established K-12 Teacher Centers throughout the state provide an existing mechanism for the colleges to work with the secondary education community. ${ }^{7}$ These centers were established in 1984 to provide systematic, ongoing professional development services to New York State teachers. More than 230,000 educators have access to the 126 center services across the state.

The leadership teams are also seriously considering opening up professional development opportunities to mathematics and science teachers in addition to the technology teachers. Another untapped group are the pre-service technology teachers in the state. Both Buffalo State College and SUNY Oswego have teacher education programs for technology teachers, and we are already working with one of the technology educators at SUNY Oswego to incorporate informed design pedagogy and NYSCATE materials into preservice teacher classrooms.

It is critically important, if the workshops are to continue to succeed, to focus on the needs of the community. What do teachers want and need? What new and improved standards based materials can be incorporated into the states' high school curriculum? How can we cultivate a 
sense of pride and accomplishment in the teachers by focusing them on doing classroom research? How can we convince the technology education community in general that classroom research about student learning is a powerful tool? These are questions that we continue to grapple with — and in our third year of funding, hope to be much closer to answering.

\section{BIBLIOGRAPHY}

1. National Academy of Engineering. Technically Speaking: Why All Americans Need to Know More About Technology. Washington, DC, National Academy Press. 2002.

2. Ibid.

3. New York State Education Department. Revisions to Part 100 of the Regulations of the Commissioner of Education. Albany, August 1999.

4. National Science Foundation. Elementary, Secondary, and Informal Education Program Solicitation and Guidelines. Washington, DC, 2000.

5. New York State Education Department. Basic Education Data System. May 2001.

6. Ibid.

7. New York State Teacher Centers, 2004, www.nyiteez.org/NYteachercenters

DONALD MARTEL

Donald Martel is a technology teacher at Northville Central School, Northville NY.

MARTY WAFFLE

Marty Waffle is Assistant Professor of Computer Information Systems and Computer Science at FultonMontgomery Community College, Johnstown NY.

PEGGIE WEEKS

Peggie Weeks is Associate Director of the Center for Technological Literacy, Hofstra University, Hempstead NY. 